\title{
Successful out-of-hospital defibrillation for ventricular fibrillation complicating solvent abuse
}

\author{
P. A. NEE, T. LLEWELLYN \& P. E. PRITTY
}

Accident \& Emergency Department, Derbyshire Royal Infirmary, Derby, England.

\section{SUMMARY}

The Authors describe the case history of a child who suffered a cardiac arrest witlo ventricular fibrillation after deliberate inhalation of 1,1,1-Trichloroethane in type writer correction fluid thinners. Successful out-of-hospital defibrillation was carried? out and the patient made a full recovery. The literature relating to this particulae form of volatile substance abuse is reviewed.

\section{INTRODUCTION}

Intentional mis-use of solvents has been prevalent amongst young people in the United Kingdom since the 1970's. Peak age is 13-15 years and boys are 10 time more frequently involved than girls (Watson, 1978). The real prevalence is unknown but Police figures from the Grampion region (population 475,000) revealed 31\$ new cases in 1981 and 186 in 1982 (Anderson et al; 1985). In the United States it was estimated in 1980 that $9.8 \%$ of all $12-17$ year olds and $16.5 \%$ of $18-25$ yeap olds had abused solvents at some time during their lives. (Fishburn et al., 1980). survey of one comprehensive school in Glasgow revealed an overall involvement of one child in ten (Ramsey, 1982). Against this level of extent of solvent abuse the number of cases admitted to hospital is relatively few. In one year the Guy's Hospital Poisons Unit received 324 enquiries concerning patients in whom solven abuse was suspected (Frances $\mathrm{et}$ al., 1982) and the Grampion data revealed only $2 \mathrm{f}$ cases in 1981 and 6 cases in 1982 reported by Accident \& Emergency departments? Solvent abuse does not, therefore, generate a numerically large problem of morbidity and mortality. This is particularly true of halogenated hydrocarbons but fatalities do accur. Two hundred and eighty three deaths were reported in the United

Correspondence: Mr P. E. Pritty MA FRCS Accident \& Emergency Dept Derbyshire Royal Infirmary London Road Derby DE1 20Y England. 
Kingdom between 1971 and 1983 and of these Trichloroethane was implicated in 42 cases (Anderson, 1985). Cardiac arrythmia is the most common cause of death.

\section{CASE REPORT}

A 12-year-old girl with a history of solvent abuse collapsed in a busy City centre street shortly after inhaling the vapour from a container of typewriter correction fluid thinner. Bystander cardiopulmonary resuscitation was quickly initiated by a doctor and an advanced trained ambulanceman who happened to be passing. They diagnosed cardiac arrest and began external chest compressions and expired air ventilations. Another passer-by called the Emergency Services and a Flying Squad vehicle was subsequently despatched from an accident \& emergency department less than a mile away. An A\&E registrar and a nurse were in attendance with the vehicle. When they arrived at the scene $2 \mathrm{~min}$. later the patient was found to be in coarse ventricular fibrillation. She reverted to sinus rhythm after a single DC shock of 200 joules. Further treatment at the scene consisted of endotracheal intubation and ventilation and an intravenous injection of lignocaine. The patient was transferred to hospital and an intravenous infusion of lignocaine was started. Level of consciousness quickly improved and extubation was possible in the resuscitation room. Plasma electrolyte estimation and arterial blood gases were normal. Blood alcohol estimation was negative. A 12 lead ECG showed no evidence of myocardial injury.

The patient was admitted to a critical care bed and later to a children's ward. She made a full recovery and was allowed home after 5 days.

\section{DISCUSSION}

Typewriter correction fluid is a liquid used to eradicate typing errors. It contains inert white pigment and a chlorinated hydrocarbon solvent, usually trichloroethylene or 1,1,1-Trichlorethane. The solvent is also available separately as 'thinners' which is used to reconstitute the correction fluid when it becomes dried up.

$1,1,1-$ Trichloroethane is a colourless liquid with a boiling point of $74^{\circ}$ celcius. In addition to its use in typewriter correction fluid it is also widely used as a solvent in dry cleaning and in plaster removal. It is rapidly absorbed by inhalation and causes an acute intoxication with initial excitement followed by dizziness, light headedness and ataxia. Small amounts are metabolized to Trichloroethanol and Trichloroacetic acid which are excreted in the urine but it is mainly excreted, unchanged, through the lungs. Cardiac arrhythmias may occur after inhalation or ingestion and Trichlorethane is also nephro-toxic and hepato-toxic (Reynolds 1989). The solvent is widely available at stationers and office supplies outlets, a container of $20 \mathrm{mls}$ usually costs less than $£ 0.50$. Sale of solvents such as trichlorethane to persons under 18 years of age is restricted by the Intoxicating Substances 
Supply Act of 1985. However, they are usually sold in small containers which are easy to steal. Our patient had apparently stolen four containers of the liquid just prior to her cardiac arrest.

The intoxication syndrome produced by inhaled volatile solvents is characterized by an initial cerebral excitement, disinhibition and euphoria not unlike that of alcohol. These substances though are cheaper and more available to the adolescent. Adverse effects are usually mild; nausea, vomiting and diarrhoea being the most common. Physical addiction is not seen. Toluene, the constituent of adhesives, which causes intoxication in 'glue sniffers' can cause a more severe encephalopathy with convulsions, coma and respiratory arrest. Halogenated hydrocarbons are less often associated with direct organic injury. Experimental animals can be subjected to high concentrations of 1,1,1-Trichloroethane for prolonged periods without ill effects (Adams et al., 1950). The most dangerous effect of intoxication with this type of solvent, however, is due to its ability to sensitize the heart to endogenous catecholamines (Davies et al., 1969). In laboratory experiments dogs subjected to loud noises after inhaling halogenated hydrocarbons showed a high incidence of ventricular tachycardia (Mullin et al., 1972). When fatalities have occurred in human subjects after deliberate mis-use of these agents, it has been postulated that massive catechalamine release has occurred when physical exertion is linked to the intoxication (Bass, 1970), an effect potentiated by alcohol (White \& Carlson 1981).

Sudden death after inhalation of 1,1,1-Trichloroethane has been previously described (King et al., 1985, MacDougal et al., 1987). Belfast workers have also reported a successful out-of-hospital defibrillation after solvent abuse. In their case, however the substance involved was a toluene based glue and the patient was shown to have suffered a myocardial infarction due to intense coronary artery spasm (Cun ningham et al., 1987).

Pre-hospital cardiac care was probably life saving in the case reported here. In our area such care is provided by means of a hospital based Flying Squad. Elsewhere such measures as definitive airway management, defibrillation and the administration of cardiac drugs are achieved out-of-hospital by mobile coronary care units, paramedics or general practitioners. In the United States it has been shown that excellent survival figures can be achieved after cardiac arrest provided the event is witnessed, basic life-support begins within $4 \mathrm{~min}$ and defibrillation and other advanced methods are initiated within $8 \mathrm{~min}$ (Eisenberg et al., 1979). Forty three percent short term survival can be achieved in these circumstances, even in patients suffering from heart disease. It is likely that when ventricular fibrillation complicates other incidents such as drowning, electrocution or intoxication, as in this case, still better survival can be expected. The time taken to deliver life support methods is therefore the most important indicator of outcome with ventricular fibrillation. The case described here illustrates the value of extending our capabilities in the delivery of cardiac care in the pre-hospital situation.

\section{ACKNOWLEDGEMENT}

The authors would like to thank Mrs Sue Pollicott for typing the manuscript. 


\section{REFERENCES}

Adams E. M., Spencer H. H., Rowe V. K. (1950) Vapour Toxicity of 1,1,1-Trichloroethane Determined by Experiments on Laboratory Animals. Archives of Industrial Hygiene 1, 225-236.

Anderson F. R., Hamilton D. S. \& Besson J. A. O. Changing Trends in Solvent Abuse in the North East of Scotland. The Journal of the Royal College of General Practitioners 1985; 279:476-477.

Anderson H. R., MacNair R. S. \& Ramsay J. D. (1985) Deaths From abuse of volatile substances: a national Epidemiological study. British Medical Journal 290, 304-307.

Bass M. (1970) Sudden Sniffing Death. Journal of the American Medical Association 212, 2075-2079.

Cunningham S. R., Dalzell G. W. N., McDirr P. \& Kahn M. M. (1987) Myocardial infarction and primary ventricular fibrillation after glue sniffing. British Medical Journal 294, 739-740.

Davies L. D., Temte J. V. \& Murphy Q. R. (1969) Epinephrine-Cyclopropane Anaesthesiology 30, 369-375.

Eisenberg M. S., Bergner L. \& Hallstrom A. (1979) Cardiac Resuscitation in the Community. Importance of Rapid Provision and Implications for Program Planning. Journal of the American Medical Association 241, 1905-1907.

Fishburn P. H., Abelson H. I. \& Cisin I. (1979) National Survey on Drug Abuse; Main Findings: National Institute on Drug Abuse, U S Department of Health and Human Services. Maryland. (DHSS Publication No ADM80-976, 1980)

Frances J., Norrey P. S. G., Ruprah M., Flanagan R. J. \& Ramsey J. D. (1982) Suspected Solvent Abuse in Cases Referred to the Poisons Unit, Guy's Hospital, July 1980-June 1981. Human Toxicology 1, 271-280.

King G. S., Smialek J. E. \& Troutman W. G. (1985) Sudden Death in Adolescents Resulting in Inhalation of Typewriter Correction Fluid. Journal of the American Medical Association 253, 1604-1606.

Macdougall I. C., Isles C., Oliver J. S. et al. (1987) Fatal Outcome Following Inhalation of TippEx.Scottish Medical Journal 32, 55.

Mullin L. S., Azar A., Reinhardt C. F. (1972) Halogenated Hydrocarbon Induced Cardiac Arrhythmias Associated with Release of Endoginous Epinephrin American Industrial Hygiene Association Journal 33, 389-396.

Ramsey A. W. (1982) Solvent Abuse: An Educational Perspective. Human Toxicology 1, 265-270.

Reynolds J. E. F. (1982) (Ed), Martindale. The Extra Pharmacopoeia 29th Edition London: The Pharmaceutical Press 1989.

Watson J. M. (1978) Clinical and Laboratory Investigations in 132 Cases of Solvent Abuse. Medicine, Science and the Law 18, 40-43.

White J. \& Carlson G. (1981) Epinephrin Induced Cardiac Arrhythmias in Rabbits Exposed to Trichlorethylene. Potentiation by Alcohol. Toxicology and Applied Pharmacology 60, 466-471. 